\title{
Vivências com os Macuxi da região do baixo São Marcos - Terra Indígena São Marcos (RR)
}

\author{
Sandra Kariny Saldanha de Oliveira ${ }^{\mathrm{a}}$, Márcia Teixeira Falcão ${ }^{\mathrm{a}^{*}(\mathbb{C})}$ \\ ${ }^{a}$ Universidade Estadual de Roraima, Brasil \\ *Autor correspondente (marciafalcao.geog@uerr.edu.br)
}

\section{N F O}

\section{Keywords}

ethnoscience

ethnicity macuxi

traditional knowledge
Palavras-chaves

etnociência

etnia macuxi

saberes tradicionais

\begin{abstract}
A B S T R A C T
Experiences with the Macuxi in the lower São Marcos region - São Marcos Indigenous Territory (RR) Ethnoscientific researches have contributed to the understanding of the traditional knowledge of the peoples. This article aims to present information related to the ethno-knowledge of the Macuxi ethnic group (Terra Indígena São Marcos-TISM) - Roraima. Environmental knowledge reveals information about the practices, use and management of natural resources specific to their ethnicity and habitat. Studies of this nature reinforce the importance of traditional communities in the protection of natural resources and bring visibility to traditional ecological knowledge, in spaces of dialogue that make it possible to identify, evaluate, analyze and monitor the conditions of use, management and sustainability of natural resources in IT. Indigenous communities have a complex and varied knowledge about biodiversity, and in the case of the Macuxi of Baixo São Marcos, especially because they have been little studied in this regard, it is necessary to understand and respect their knowledge and practices in a broader context, as well as informing them of the local strengths and weaknesses. Studies of this nature reinforce the importance of relations between these indigenous communities and biodiversity, valuing and bringing visibility to their ethno-knowledge.
\end{abstract}

\section{R E S U M O}

As pesquisas etnocientíficas têm contribuído para o entendimento dos saberes tradicionais dos povos, o presente artigo tem como objetivo apresentar informações relativas ao etnoconhecimento da etnia macuxi (Terra Indígena São Marcos-TISM) - Roraima. O saber ambiental revela informações sobre as práticas, uso e manejo dos recursos naturais próprios de sua etnia e de seu habitat. Estudos desta natureza reforçam a importância das comunidades tradicionais na proteção dos recursos naturais e trazem visibilidade ao conhecimento ecológico tradicional, em espaços de diálogo que possibilitam identificar, avaliar, analisar e monitorar as condições de uso, manejo e sustentabilidade dos recursos naturais nas TIs. As comunidades indígenas são portadoras de um conhecimento complexo e variado sobre a biodiversidade, e no caso dos Macuxi do Baixo São Marcos, em especial por terem sido ainda pouco estudados neste sentido, é necessário compreender e respeitar seus saberes e práticas num contexto mais amplo, assim como informá-los sobre as potencialidades e fragilidades locais. Estudos desta natureza reforçam a importância das relações entre estas comunidades indígenas e a biodiversidade, valorizando e trazendo visibilidade ao etnoconhecimento que possuem. 


\section{INTRODUÇÃO}

O etnoconhecimento contribui para a compreensão dos saberes tradicionais dos povos e dos modos de vida construídos nas inter-relações ser humanos e ambientes (Haverroth, 2013). Esta ciência é compreendida por meio da investigação do saber-fazer e sobre o uso e manejo dos recursos naturais pelas populações tradicionais.

Sob o ponto de vista cultural, esses estudos mostram à visão de mundo e das práticas culturais e simbólicas das chamadas comunidades tradicionais (Diegues, 2000). No caso dos povos indígenas, por questões históricas, culturais e do ambiente onde a maioria reside, essa relação costuma ser mais "estreita" com os elementos do meio natural e nas vivências construídas nas inter-relações ser humanoambiente (Haverroth, 2013).

O papel das comunidades indígenas na conservação da biodiversidade é reconhecido em vários acordos internacionais, entre os quais, a Convenção da Diversidade Biológica - CDB e a Agenda 21 (Santilli, 2001). Outra linha de discussões internacionais sobre os "conhecimentos tradicionais" que ganhou proporção depois do advento da CDB se deu através da valorização dos povos indígenas como possuidores de modelos de adaptação ecológica, apoiados no que se convencionou chamar de conhecimento ou saber ecológico tradicional, isto é, o conhecimento que populações locais têm de cada detalhe do seu entorno, do ciclo anual, das espécies animais e vegetais, e dos solos (Oliveira, 2012).

As comunidades indígenas representam um grande potencial para proteção, conservação e uso racional de seus recursos naturais, sendo portadoras de um conhecimento complexo e variado sobre a biodiversidade. No campo de saberes tradicionais, ainda que não seja possível a diferentes grupos explicar uma série de fenômenos observados, as ações práticas respondem por um entendimento formulado na experiência das relações com a natureza, informando o processo de acumulação de conhecimento através das gerações (Castro, 2000).

Estudos desta natureza reforçam a importância das comunidades tradicionais na proteção dos recursos naturais e trazem visibilidade ao conhecimento ecológico tradicional, em espaços de diálogo que possibilitam identificar, avaliar, analisar e monitorar as condições de uso, manejo e sustentabilidade dos recursos naturais nas TIs.

Neste sentido, as comunidades locais vêm desenvolvendo sistemas próprios de classificação e manejo de espécies vegetais, resultantes do acúmulo de conhecimento prático ao longo do tempo, possibilitando suprir suas necessidades (Strachulski e Floriani, 2013).
No âmbito dos trabalhos realizados na região Amazônica, na interface entre natureza/cultura, essa característica continua relativamente marcante: praticamente, todo o cotidiano de uma aldeia indígena gira em torno do manejo de recursos naturais ou cultivo de plantas, no caso dos povos indígenas, por questões históricas, culturais e do ambiente onde a maioria desses povos vive, essa relação costuma ser mais estreita (Haverroth, 2013).

Nessa perspectiva, o presente artigo tem como objetivo apresentar informações sobre as práticas, uso e manejo dos recursos naturais relacionados ao etnoconhecimento ddo povo Macuxi que habita a terra indígena São Marcos-TISM.

\section{MATERIAL E MÉTODOS}

\section{Localização da área de estudo}

A TISM está no Brasil, estado de Roraima e faz fronteira com a Venezuela. Pela divisão territorial brasileira está entre os municípios de Pacaraima e Boa Vista. Limita-se também com outras terras indígenas: Raposa Serra do Sol, Anaro, Ouro e Ponta da Serra (Manduca et al., 2009) (Figura 1).

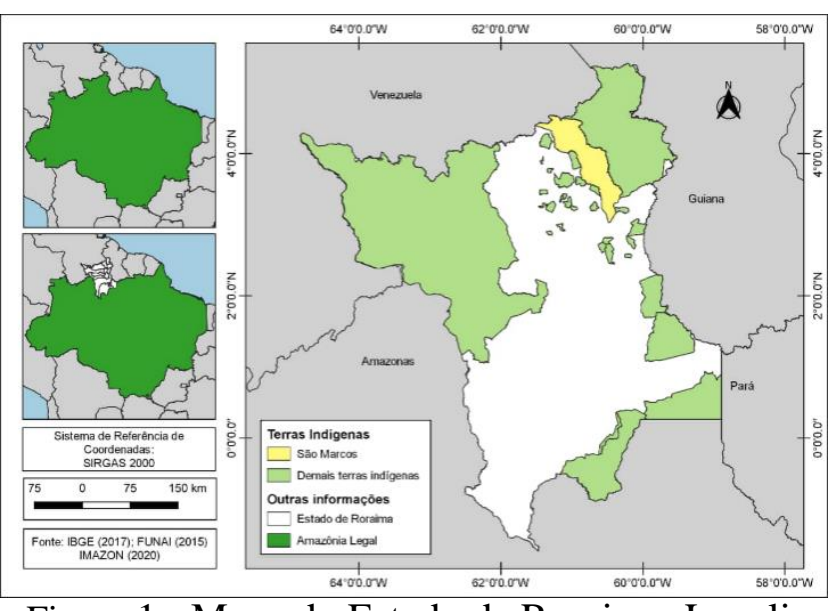

Figura 1 - Mapa do Estado de Roraima, Localização das Terras Indígenas e da Reserva São Marcos.

A TISM foi demarcada e homologada pelo Decreto $\mathrm{n}^{\circ} 312$ de 29 de outubro de 1991, possui área total de 654.110 hectares (Instituto Socioambiental - ISA, 2010), 43 comunidades distribuídas em três etnias: Macuxi, Taurepang (ambas de filiação linguística Karib) e Wapixana (de filiação linguística Aruak). Estas vivem em três regiões: Alto, Médio e Baixo São Marcos, são constituídas basicamente pelas etnias Macuxi e Taurepang (de filiação linguística Karib) e Wapixana (de filiação linguística Aruak). Na região do Baixo São Marcos estão situadas as comunidades alvo deste estudo, onde predomina a etnia Macuxi: Vista Alegre, fundada em 
1956 (60 anos) e Darora, em 1961 (55 anos) possuem uma população de 620 e 184 habitantes, res- pectivamente. A etnia Macuxi predomina em ambas as comunidades (Figura 2).

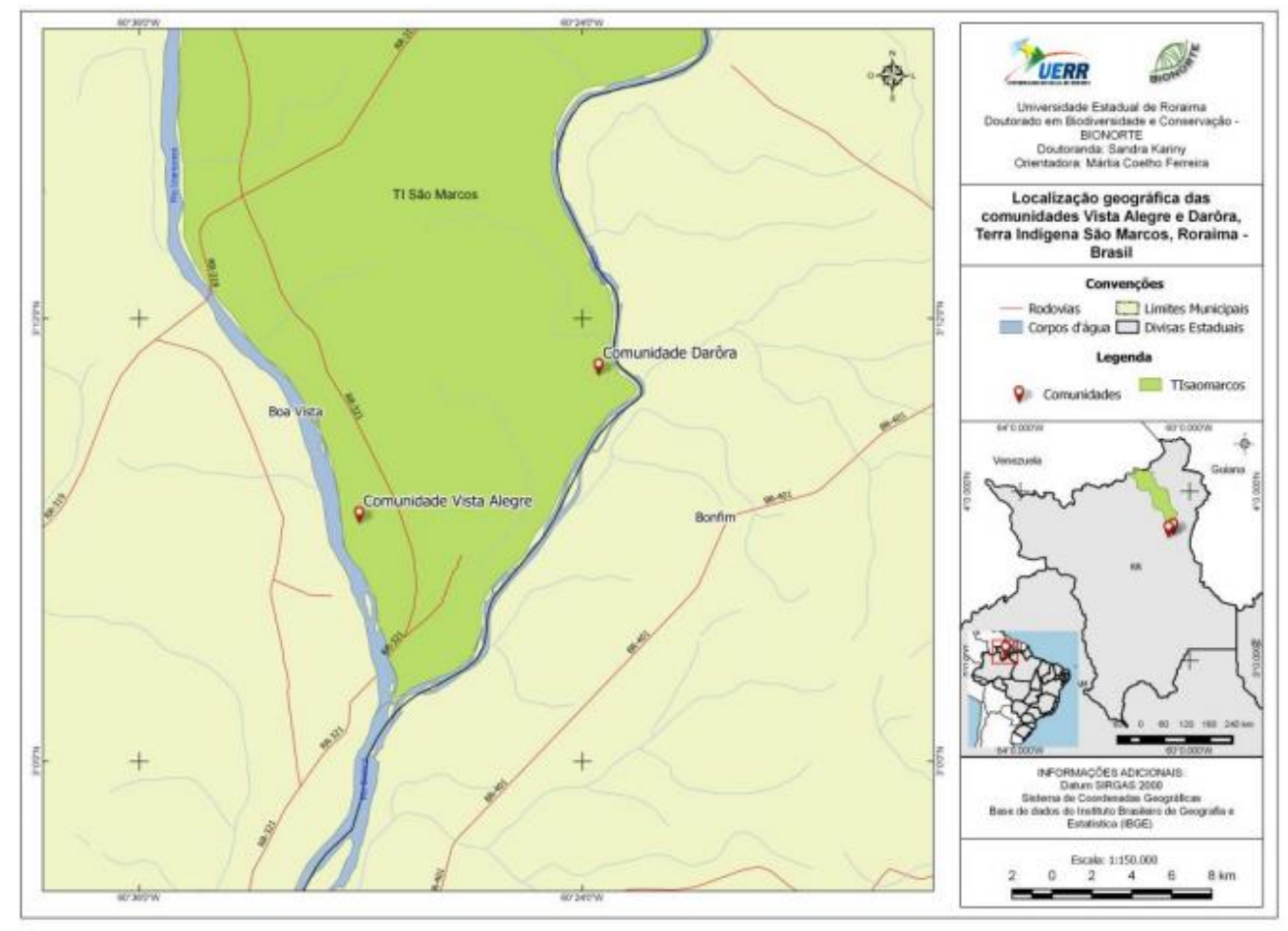

Figura 2 - Localização das comunidades foco deste estudo (Oliveira, 2016).

A vegetação da TISM é caracterizada pela presença de floresta ombrófila e lavrado, denominação local para savana (Figura 3). As savanas roraimenses, conhecidas regionalmente como lavrado (Barbosa e Miranda, 2005) se constituem como as maiores áreas de savanas da Amazônia brasileira, fazendo parte do complexo paisagístico "Rio BrancoRupununi”, que se estende para a Guiana e Venezuela (Barbosa e Miranda, 2005; Barbosa et al., 2007). Inventários fitofisionômicos realizados em diferentes áreas de savanas brasileiras têm apontado uma distância florística das localizadas na Amazônia, com especial destaque para Roraima, onde as mesmas são isoladas e pobres em espécies vegetais arbóreas (Barbosa e Miranda, 2005). O lavrado, ambiente predominante nas comunidades estudadas, geralmente apresenta relevo plano (60$160 \mathrm{~m})$, podendo apresentar pequenas ondulações, entremeadas por veredas de buritis e lagoas, parcial ou totalmente drenadas por igarapés (Santos et al., 2013). É dominado por duas categorias fisionômicas, que são as áreas abertas (não florestal) e florestal. Os ambientes não-florestais são as savanas verdadeiras, cobrindo cerca de $70 \%$ da região, e agrupando todos os sistemas não-florestais, sendo estes constituídos por matas estacionais, ombrófilas e de contato (ecótonos) (Barbosa e Miranda, 2005; Campos et al., 2008). As principais espécies domi- nantes no lavrado roraimense são o caimbé (Curatella americana), murici (Byrsonima crassifolia), sucuba (Himatanthus articulatus) e paricarana (Bowdichia virgilioides) (Barbosa e Miranda, 2005). O conhecimento científico das relações etnoambientais, ecológicas e produtivas deste macro ecossistema regional (Barbosa et al., 2005), aliado aos conhecimentos tradicionais destes povos se complementam para o aproveitamento racional das áreas de savana de Roraima.

O clima dos lavrados é o tropical monçônico do tipo Awi (tropical úmido sem estação fria), com altas temperaturas médias durante o ano e estação seca acentuada com pico entre dezembro e março e a chuvosa entre maio e agosto (Barbosa e Miranda, 2005). A temperatura média mensal é praticamente constante ao longo do ano $\left(27,8 \pm 0,6^{\circ} \mathrm{C}\right)$, não variando além de $5^{\circ} \mathrm{C}$ entre as médias das máximas e mínimas (Santos et al, 2013).

No Estado de Roraima, foco deste estudo, atualmente habitam nove etnias indígenas: Ingarikó, Macuxi, Patamona, Taurepang, Waimiri-Atroari, Wapixana, Waiwaí, Yanomami, Ye'kuana, a filiação linguística se apresenta em três famílias linguísticas: Aruak (Wapichana), Karib (Macuxi, Taurepang, Ingarikó, Ye'kuana, Sapará, Wai Wai, Waimiri Atroari e Patamona) e Yanomami. Algumas destas etnias estão nas áreas de savanas, seus 
falantes entendem-se com muita facilidade, indicando que tais grupos falariam dialetos de uma mesma língua comum, a "língua Pemon/Kapon", originada da língua Karib. Pemon é o termo usado pelos macuxi e taurepang para se auto denominarem, Kapon é a autodenominação dos Ingarikó e dos Patamona (Miller et al, 2008). Os indígenas macuxi são habitantes da região fronteiriça entre a
República Bolivariana da Venezuela e República Cooperativa da Guiana, entre as cabeceiras dos rios branco e Rupununi, em território politicamente partilhado entre Brasil e Guiana $\mathrm{O}$ contingente mais expressivo da população Macuxi encontra-se em maior número de comunidades nas terras indígenas Raposa Serra do Sol e São Marcos (Santilli, 1997).

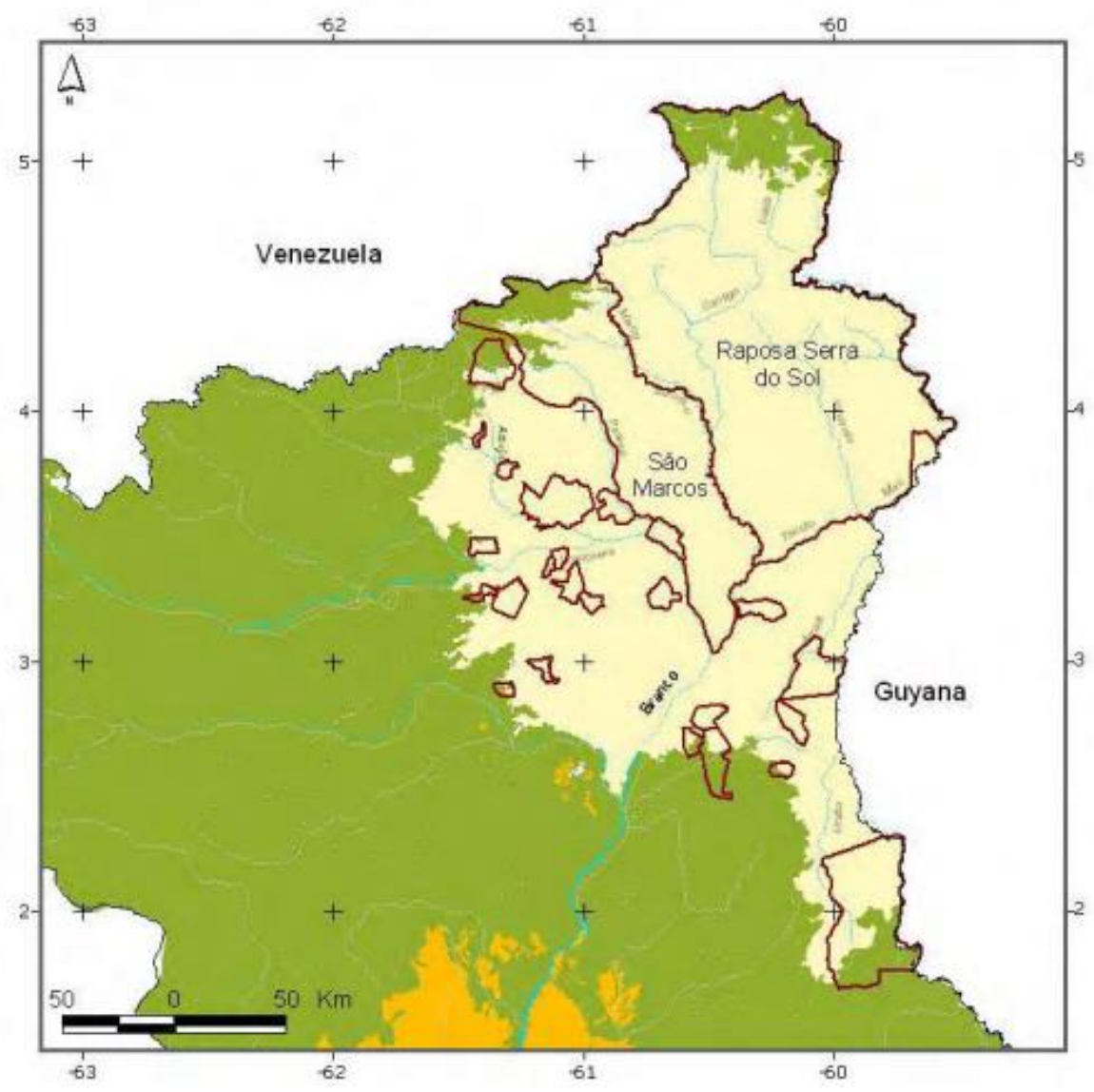

Figura 3 - Mapa da vegetação da área de estudo (verde - floresta; amarelo claro - savana/lavrado roraimense) (Barbosa et al., 2007).

\section{Métodos Participativos}

A pesquisa envolver autorizações da Comissão Nacional de Ética em Pesquisa (CONEP) $\left(n^{\circ}\right.$ 820.111), do Comitê de Ética em pesquisa da Universidade Federal de Roraima (CEP/UFRR) parecer ( $n^{\circ}$ 953.257), do Instituto do Patrimônio Histórico e Artístico Nacional - IPHAN (nº 09/2014) e da Fundação Nacional do Índio (FUNAI) processo $n^{\circ}$ 68/AAEP/PRES/2014.

A realização da pesquisa nas comunidades indígenas ocorreu mediante reuniões nas comunidades indígenas para expor o planejamento (Finalidade e importância da pesquisa, o que será pesquisado, como será pesquisado, período de estudo, resultados e impacto da pesquisa), após a explanação foi pedido autorização por escrito no Termo de Anuência Prévia (TAP).

Assim, o dossiê contendo o projeto de pesquisa, o TAP e os relatórios das reuniões foram encaminhados ao IPHAN, então responsável pela autorização de pesquisa com acesso ao conhecimento tradicional associado à biodiversidade para fins de pesquisa científica e sem acesso ao patrimônio genético. O projeto foi ao mesmo tempo encaminhado à FUNAI, solicitando autorização de ingresso e pesquisa na área indígena. Esta última autorização foi subsidiada pelo parecer de mérito científico do CNPQ.

O projeto foi ainda cadastrado na Plataforma Brasil, base nacional e unificada de registros de pesquisas envolvendo seres humanos, para apreciação do Comitê Nacional de Ética em Pesquisa (CONEP) e Comitê de ética em pesquisa com seres 
humanos (CEP).

Conforme instruções do CEP, CONEP e Resolução 466/12 para pesquisas com seres humanos, todos os interlocutores entrevistados na execução da pesquisa assinaram em duas vias o termo de consentimento livre e esclarecido (TCLE). Na leitura do TCLE a pesquisadora explicava os objetivos da pesquisa, da abordagem metodológica, do conteúdo das perguntas, os possíveis desconfortos e benefícios oriundos deste trabalho. Ao autorizar a realização da entrevista, a coleta de dados foi iniciada e cada indígena assinava o TCLE concordando, com a divulgação dos dados e das informações.

Os métodos utilizados na pesquisa foram qualitativos devido à importância destes para compreender os fenômenos estudados a partir da perspectiva de conhecimento dos sujeitos pesquisados (indígenas). Esse procedimento depreendeu de um processo de reflexão sobre os modelos produtivos e costumes, como parte do pressuposto que cada sujeito social conhece de forma peculiar a sua realidade, as estruturas e as relações (Minayo, 2000). Por isto, a metodologia abordou a pesquisa-participante, do tipo descritiva, onde todos os objetivos foram planejados, avaliados e executados com os sujeitos envolvidos, na perspectiva de integrar o saber popular e o saber acadêmico. No processo investigativo preliminar, foram realizadas visitas mensais nas comunidades, com o acompanhamento do informante em cada uma delas, o que permitiu uma aproximação com os indígenas, através da técnica da observação participante. A utilização destas e de outras técnicas, como a escolha de informantes chaves ou especialistas locais, correspondem a indivíduos portadores de verdadeiros conhecimentos acerca do fenômeno. A realização da observação participante permite contato direto entre $o$ pesquisador e o fenômeno estudado, de modo a permitir a captação de uma variedade de situações ou fenômenos que não são obtidos por meio de perguntas (Albuquerque et al., 2010). As conduções iniciais das entrevistas são livres (abertas ou nãoestruturadas), onde o informante aborda livremente o tema proposto e discursa livremente sobre seu modo de vida, tornando-se estruturadas à medida que os fenômenos vão sendo abordados (Cortez, 2010).

Para entender a realidade dos sujeitos, o diário de campo foi utilizado na tentativa de auxiliar a interpretação dos dados, o que permite ao pesquisador apresentar suas idéias, observações e concepções sobre objetos, mundo, fenômenos e acontecimentos nas comunidades indígenas pesquisadas, a partir da observação participante. A observação participante é a melhor maneira para se assegurar de que os dados coletados refletem de fato o ponto de vista do grupo pesquisado, além de compreender os contextos em que se dão os processos estudados (Amorozo e Viertler, 2010).

$\mathrm{Na}$ composição da amostra para a seleção de informantes foi utilizada a chamada "bola de neve" (snow ball) conforme Albuquerque et al. (2010), é um procedimento utilizado para a seleção intencional na qual, a partir do contato inicial com a comunidade, um primeiro especialista é reconhecido, ou seja, os informantes envolvidos são selecionados a partir de indicações feitas pelos entrevistados da comunidade, e este passa a indicar outro especialista, e assim sucessivamente, até envolver todos os especialistas da comunidade conforme interesse e disponibilidade dos inquiridos, pois o objetivo é fazer o levantamento dos saberes construídos, das práticas, da oralidade, que expressa os valores culturais da comunidade local (Albuquerque et al., 2010).

A questão do retorno da pesquisa às comunidades indígenas foi realizada em diversos momentos diante do interesse das comunidades em cursos/minicursos, oficinas e palestras certificados pela Universidade Estadual e Federal de Roraima. A contribuição da pesquisa às populações da TISM ocorreu nos cursos, elaboração do livro didático infantil, projetos escolares, procedimentos teórico-metodológicos do planejamento escolar para professores indígenas do Baixo São Marcos/RR, etnomapeamento comunitário, entre outros temas e atividades indiretamente associados à presente investigação. Todas as atividades foram realizadas em ambas comunidades, e integram o retorno comprometido da pesquisadora.

\section{RESULTADOS E DISCUSSÃO}

No Baixo São Marcos, localização do estudo, o lavrado (savana) é o ecossistema dominante, usado como fonte de recursos e como áreas de cultivo agrícola pelos indígenas do lavrado. "O aproveitamento racional das áreas de savana de Roraima passa, sem dúvida, pelo amplo conhecimento científico das relações etnoambientais, ecológicas e produtivas deste macroecossistema regional" (Barbosa e Miranda 2005 p.63).

A conservação dos ecossistemas locais e dos sistemas tradicionais de produção de alimentos contribui para a manutenção de uma vida saudável das comunidades indígenas (Pedreira et al., 2013).

A agricultura praticada é de subsistência e comercial, em cada comunidade existe uma associação de agricultores que comercializa os produtos advindos do trabalho dos associados. Vale salientar que esta área é marcada por desafios ecológicos, pois o lavrado representa um universo de recursos 
mínimos, o que exigiu dos indígenas engenhosas soluções, em termos de experiência e praticidade na infinita relação cultura versus natureza, condição que lhes garante sobreviver com um mínimo de recursos disponibilizados pelo meio (Costa e Souza, 2005). A mandioca e o feijão formam a base alimentar das comunidades e são os principais elementos de suas plantações, sendo a farinha de mandioca o alimento básico de toda a população.

A pesca e a caça dão fontes de proteína e tem grande relevância nutricional na dieta das comunidades, visto que um dos pratos típicos nas duas comunidades indígenas, é a base de peixe cozido e pimenta, iguaria conhecida como damurida.

Os povos indígenas que vivem em áreas de lavrado em Roraima são agricultores, pescadores, caçadores e coletores, com um vasto conhecimento acumulado sobre o ambiente e sobre técnicas tradicionalmente utilizadas (Oliveira et al., 2005). A conservação dos ecossistemas locais e dos sistemas tradicionais de produção de alimentos contribui para a manutenção de uma vida saudável das comunidades indígenas (Pedreira et al., 2013), onde o componente vegetal e a cultura local constituem um sistema coexistente de conhecimentos acerca da relação população humana e planta (Guarim Neto e Carniello, 2007).

A organização das comunidades ocorre da seguinte forma: Tuxaua (líder), segundo tuxaua que representa o primeiro e atua na realização dos trabalhos comunitários tais como reuniões, resoluções de problemas e conflitos e trabalhos coletivos. Os tuxauas contam ainda com os capatazes que auxiliam nos trabalhos na comunidade. As comunidades indígenas e todos os povos indígenas da TISM estão filiados à Associação dos Povos Indígenas da Terra São Marcos (APITSM), que apresenta dois postos de representação: comunidade Surumu, município de Pacaraima (RR), e balsa do passarão, município de Boa Vista-RR, são membros todos os indígenas da TISM que estejam empenhados na luta do movimento indígena na defesa de seus territórios.

A APITSM tem como uma das finalidades: "promover integração a outras entidades ligadas a ações indígenas na defesa do território Indígena da Região São Marcos e do seu meio ambiente, visando à geração e transferência de conhecimentos, tecnologias de preservação e intercâmbio de programas e projetos indígenas, principalmente no que tange à flora, fauna e recursos hídricos" (APITSM, Art. $2^{\circ}$, inciso II).

A APITSM é formada por uma coordenação geral, com mandato de três anos, concorrem até dois candidatos ao cargo de coordenador e vice-coordenador que são indicados por cada região da TISM, onde são escolhidos em reunião do conselho deliberativo, coordenação geral e conselho fiscal, para assim serem enviados os seus nomes às comunidades para que votem nos candidatos de sua preferência, sendo os votos apurados na assembleia geral.

Dessa forma, no conhecimento prático humano (tradicional ou local) existem informações detalhadas de caráter taxonômico sobre paisagens, vegetação, processos biológicos e ecológicos, fenômenos de recuperação de ecossistemas ou de manejo da paisagem, não se restringindo aos aspectos estruturais da natureza, ou que se refere a dimensões dinâmicas (de padrões e processos), relacionais (ligados as relações entre os elementos e os eventos naturais) e utilitárias dos objetos e recursos naturais (Toledo e Barrera-Bassols, 2009).

\section{CONCLUSÕES}

As comunidades indígenas são portadoras de um conhecimento complexo e variado sobre a biodiversidade, e no caso dos Macuxi do Baixo São Marcos, em especial por terem sido ainda pouco estudados neste sentido, é necessário compreender e respeitar seus saberes e práticas num contexto mais amplo, assim como informá-los sobre as potencialidade e fragilidades locais. Estudos desta natureza reforçam a importância das relações entre estas comunidades indígenas e a biodiversidade, valorizando e trazendo visibilidade ao etnoconhecimento. Ademais, se configura como um aporte à manutenção $\mathrm{e}$ valorização de suas tradições. Para tanto, há de se envolver os próprios indígenas na documentação desses saberes.

\section{AGRADECIMENTOS}

Ao povo Macuxi em especial as comunidades Darora e Vista Alegre.

\section{REFERÊNCIAS BIBLIOGRÁFICAS}

Albuquerque UP, Lucena RFP, Alencar NL. Métodos e técnicas para coleta de dados etnobiológicos. In: Albuquerque UP, Lucena RFP, Cunha LVF (Org) Métodos e técnicas na pesquisa etnobiológica e etnoecológica. Recife: Nupeea, p.41-64, 2010

Albuquerque UP, Lucena RFP, Lins Neto EMF. Seleção dos participantes da pesquisa. In: Albuquerque UP, Lucena RFP, Cunha LVFC. (Org.). Métodos e técnicas na pesquisa etnobiológica e etnoecológica. Recife-PE: NUPEEA, 2010. (Col. Estudos e avanços).

Amorozo MCM, Viertler RB. A abordagem qualitativa na coleta e análise de dados em etnobiologia e etnoecologia. In: Albuquerque UP, Lucena RFP e Cunha LVF. (Orgs.). Métodos e técnicas na pesquisa etnobiológica e etnoecológica. Recife: Nupeea, p.67-82, 2010. 
Andrello G. Fazenda São Marcos: de próprio Nacional a Terra Indígena. In: Barbosa RI, Melo VF. (Orgs.). Roraima: homem, ambiente e ecologia. Boa Vista: FEMACT, 2010.

Associação dos Povos Indígenas da Terra São Marcos-APITSM. Estatuto Social da Associação dos Povos Indígenas da Terra São Marcos. Boa Vista. 2005.

Barbosa RI, Campos C, Pinto F, Fearnside PM. The "Lavrados" of Roraima: Biodiversity and Conservation of Brazil's Amazonian Savannas. Functional Ecosystems and Communities, v.1, n.1, p.29-41, 2007.

Barbosa RI, Miranda IS. Fitofisionomias e diversidade vegetal das savanas de Roraima. In: Barbosa RI, Xaud HAM, Souza JMC. (Orgs.). Savanas de Roraima: etnoecologia, biodiversidade e potencialidades agrosilvipastoris. Boa Vista: FEMACT, p.61-78, 2005.

Campos C, Pinto F, Barbosa RI. The Lavrado Roraima: biological importance, development and conservation in the greater Savannah Biome (Diagnostics). Boa Vista: INPA, 2008.

Castro E. Território, biodiversidade e saberes de populações tradicionais. In: Diegues A CS. (Org.). Etnoconservação: novos rumos para a conservação da Natureza. São Paulo: Hucitec, Nupaub, p.165-182, 2000.

Cortez CS. (2010) - Conhecimento ecológico local, técnicas de pesca e uso dos recursos pesqueiros em comunidades da Área de Proteção Ambiental Barra do Rio Mamanguape, Paraíba, Brasil. Dissertação de Mestrado, 91p., Universidade Federal da Paraíba, João Pessoa, PB, Brasil.

Diegues ACS. Etnoconservação da natureza: enfoques alternativos. In: (Org.). Etnoconservação: novos rumos para a conservação da Natureza. São Paulo: Hucitec, Nupaub, p.1-46, 2000 .

Guarim Neto G, Carniello MA. Etnoconhecimento e saber local: um olhar sobre as populações humanas e os recursos vegetais. In: ALbuquerque UP, Alves AGC, Araujo TAS. Povos e Paisagens: Etnobiologia, etnoecologia e biodiversidade no Brasil. Recife: Nupeea, p.105-114, 2007.

Haverroth M. Etnobiologia, saúde e povos indígenas. In: Haverroth M. (Org). Etnobiologia, saúde e povos indígenas. Recife. Nupeea, p.37-64, 2013.

Manduca LS, Silva NM, Almeida FTde. Atlas escolar: terra indígena São Marcos. Boa Vista: UFRR, 66 p., 2009.

Minayo MCS. O desafio do conhecimento: Pesquisa qualitativa em saúde. São Paulo - Rio de Janeiro: Hucitec Abrasco, 2000.

Oliveira AR. Tempo dos netos: Abundância e escassez nas redes de discursos ecológicos entre os Wapichana na fronteira Brasil-Guiana. Brasília, 354f. Tese (Doutorado em Antropologia Social), Universidade de Brasília. 2012.

Oliveira Junior JOL, Costa P, Mourão Junior M. Agricultura familiar os lavrados de Roraima. In: Barbosa RI, Xaud HAM, Souza JMC. (Orgs.). Savanas de Roraima: etnoecologia, biodiversidade e potencialidades agrosilvipastoris. Boa Vista: FEMACT, p.155-178, 2005.

Oliveira SKS. Etnobotânica em duas Comunidades da terra Indígena São Marcos. Belém, 113f. Tese (Doutorado em
Biodiversidade e Biotecnologia), Universidade Federal do Pará. 2016.

Pedreira JL. et al. Produção de alimentos e conservação de recursos naturais na terra indígena Araçá-Roraima. In: HAVERROTH, M. (Org). Etnobiologia, saúde e povos indígenas. Recife. Nupeea, p.187-200, 2013.

Santilli J. Biodiversidade e Conhecimentos Tradicionais. In: Capobianco, J. P. R. et al. Biodiversidade na Amazônia Brasileira: Avaliação e ações prioritárias para a conservação, uso sustentável e repartição de benefícios. São Paulo: ISA, 2001

Santilli J. Homem, Ambiente e Ecologia no Estado de Roraima. Manaus: INPA. 1997. p.49-64.

Santos NMC, Vale Júnior JF, Barbosa RI. Florística e estrutura arbórea de ilhas de mata em áreas de savana do norte da Amazônia brasileira. Bol. Mus. Para. Emílio Goeldi. Ciências Naturais, v.8, n.2, p.205-221, 2013.

Sieber SS, Albuquerque UP. Métodos participativos na pesquisa etnobiológica. In: Albuquerque UP, Lucena RFP, Cunha LVF. (Org.). Métodos e Técnicas na Pesquisa Etnobiológica e Etnoecológica. Recife: NUPEEA, 2010, p.85106.

Strachulski J, Floriani N. Conhecimento popular sobre plantas: um estudo etnobotânico na comunidade rural de linha criciumal, em Cândido de Abreu-PR. Revista Geografar, v.8, n.1, p.125-153, 2013.

Toledo VM, Barrera-Bassols NA. Etnoecologia: uma ciência pós-normal que studa as sabedorias tradicionais. Revista Desenvolvimento e Meio Ambiente, v.20, n.2, p.3145,2009. https://doi.org/10.5380/dma.v20i0.14519 